\title{
A formação médica nos cenários de prática extra-hospitalares
}

NOGUEIRA, Maria Inês.

Retratos da formação médica nos novos cenários de prática.

São Paulo: Hucitec, 2013. 157p.

\section{| ${ }^{1}$ Vanessa Maia Rangel |}

${ }^{1}$ Departamento de Saúde e Sociedade do Instituto de Saúde da Comunidade. Universidade Federal Fluminense. Endereço eletrônico: vanessatufaha@hotmail.com

http://dx.doi.org/10.1590/S0103-73312014000200017

O objetivo do livro de Nogueira, Retratos da formação médica nos novos cenários de prática, é mostrar, a partir de um exemplo de reforma curricular do curso de medicina da Universidade Federal Fluminense (UFF), como se dão as possibilidades de mudanças na formação médica contemplando um "olhar ampliado". A autora parte dos conceitos de estilo de pensamento biomédico para explicar o enfoque do olhar atual da medicina na doença-lesão e percorre o caminho de mudança que seria a abordagem integral do sujeito adoecido nas suas dimensões biopsicossociais ao ponto possível da reconstrução do modo de se fazer clínica. Sua pesquisa se desenvolve, então, pela observação participante de uma nova disciplina chamada Trabalho de Campo Supervisionado, que tem a intenção de introduzir os alunos de maneira precoce em experiências de prática fora do ambiente hospitalar, valorizando os cenários da atenção básica em saúde.

No capítulo um, a autora discute a possível origem do conceito de biomedicina ou medicina científica a partir da anatomoclínica, da evidência da lesão sendo a definidora da categoria doença. Utilizando as abordagens teóricas de Camargo Jr. e Foucault, mostra como tradicionalmente é dentro do espaço hospitalar que esses conceitos se criam e se desenvolvem. No entanto, com Canguilhem acontecem a volta da pessoa doente e as dificuldades da biomedicina de corresponder às expectativas de saúde do ser em adoecimento. Explora a valorização do sofrimento, 
do cuidado, das tecnologias leves e da diretriz da integralidade como o possível caminho de mudança. Aponta que é o campo da Saúde Coletiva aquele que articula os novos conceitos, sendo esse o enfoque da formação médica atualizada.

No capítulo dois, Nogueira define sua abordagem antropológica de pesquisa baseada na observação participante e na realização de entrevistas semiestruturadas no campo da Escola Médica da UFF, na disciplina Trabalho de Campo Supervisionado I e II, durante os dois primeiros anos do curso de Medicina. A autora coloca que o objetivo desta disciplina seria proporcionar uma reflexão sobre as dimensões socioculturais do processo saúde-doença, assim como sobre a integralidade das ações de saúde.

Ainda no intuito de evidenciar os objetivos e propostas da disciplina, no capítulo três a autora enfoca a necessidade de desenvolver um olhar para a complexidade da vida humana e para o sujeito. Isto é feito pela introdução de disciplinas ligadas à Saúde Coletiva antes da iniciação no curso de anatomia humana. Para a autora, esta seria uma opção de iniciação do aluno "através da vida", já que aborda a possibilidade de uma formação médica mais "humanizada" dentro de uma discussão do que seria um bom profissional de saúde.

Nogueira mostra com detalhes de suas entrevistas como os alunos dos primeiros períodos do curso médico parecem incorporar facilmente os conceitos propostos, embora alunos de períodos posteriores questionem o valor das disciplinas da Saúde Coletiva em relação àquelas vistas como disciplinas científicas. Fica claro o conflito, evidenciado pela fala dos alunos, entre a razão prática baseada no saber interpretativo do conhecimento científico, visto como o essencial. No entanto, a autora aponta que os alunos capturam as intenções da disciplina e são capazes de entender a proposta ético-humanista embutida na reforma do curso.

O capítulo quatro é marcado pela importância do território e da multi e interdisciplinaridade na formação dos preceptores da disciplina Trabalho de Campo Supervisionado, com o objetivo de propor aos alunos a entrada em "cenários da vida real" ao mesmo tempo em que utilizam diferentes abordagens teóricas. A autora coloca também o enfoque na importância da comunicação por parte dos alunos, da valorização dos sentimentos durante a aprendizagem, do trabalho em equipe e da avaliação individualizada e discutida entre alunos e preceptores. 
Em relação aos "cenários da vida real" observados, Nogueira destaca o trabalho de campo com a população idosa, evidenciando a discussão sobre o processo de envelhecimento, a dificuldade de enfrentar as unidades de saúde e seus profissionais, vistos como não acolhedores, a questão da sexualidade e do prazer na idade avançada e a necessidade de se olhar para o idoso de maneira integral e humana. Outro destaque se dá na observação dos cenários de assistência aos pacientes portadores de HIV e Aids. A autora escolhe as ONGs como espaços de aprendizado e troca, sendo o local onde as vivências dos portadores dos agravos são valorizados, ficando o adoecimento em segundo plano. Esses espaços comportam desde ambulatórios e salas de entrevistas, além de refeitórios, cozinhas, dormitórios e espaços de recreação.

O capítulo cinco aborda a experiência da disciplina estudada na atenção básica, objetivando mostrar aos alunos a estrutura, o funcionamento e a importância da atenção básica dentro do Sistema Único de Saúde. Destaca-se a observação dos processos de formação dos vínculos com os usuários, a integração das atividades das unidades estudadas com a comunidade e a possibilidade da utilização de outras racionalidades médicas nas ações de saúde. Nogueira aponta para a possibilidade do resgate da dimensão cuidadora e da medicina poder ser construída como prática essencialmente relacional e da possibilidade deste aprendizado, evidenciada nas falas dos alunos entrevistados.

Em discussão dos resultados do trabalho, Nogueira destaca que, apesar de algumas críticas por parte dos alunos e preceptores em relação ao tempo dispendido com a disciplina e à falta de comprometimento e envolvimento dos alunos com o aprendizado nos cenários fora do ambiente hospitalar, observou-se, por outro lado, uma positiva mudança de atitude por parte dos alunos interessados, a valorização da abordagem intersubjetiva da relação médico-paciente, a necessidade de se desenvolver uma escuta qualificada e a capacidade dialógica e de se ampliar a prática centrada na pessoa do paciente e do profissional de saúde.

Nogueira finaliza seu livro no capítulo sete, analisando os limites e possibilidades da Reforma Curricular da UFF. Afirma ser o papel da Saúde Coletiva fundamental para a sustentação deste processo, que a meu ver, seria mais uma reconstrução de um imaginário tradicional de médico a partir de uma imagem humanista. 
A autora coloca que, apesar dos posteriores anos da formação médica, especialmente o internato hospitalar e a residência como produtora de especialistas ser uma resistência na proposta de reforma curricular, acredita que esses primeiros anos de experiência extra-hospitalar possam ter grande influência na mudança do perfil do profissional que se deseja: um perfil generalista, um profissional ético e que saiba trabalhar a partir das tecnologias leves, visando a uma abordagem baseada na integralidade. Critica, no entanto, a falta de articulação entre os serviços de ensino-aprendizado e os cenários de prática profissional, quando o espaço extra-hospitalar não se mostra disponível à formação, fazendo com que o hospital ainda seja um território de mais fácil acesso aos estudantes universitários e, portanto, de maior influência na formação. 